\title{
An Analysis of the Energetics of Tropical and Extra-Tropical Regions under Cold ENSO Compose Episodes
}

\author{
Zayra C. Sátyro ${ }^{1}$, José A. P. Veiga ${ }^{2}$ \\ ${ }^{1}$ Post Graduation Program in Climate and Environment, National Institute for Amazonia Research (INPA) and University of the \\ Amazonas State (UEA), Manaus, Brazil \\ ${ }^{2}$ Department of Meteorology, Amazonas State University, Manaus, Brazil \\ Email:veiga.uea@gmail.com
}

How to cite this paper: Sátyro, Z.C. and Veiga, J.A.P. (2017) An Analysis of the Energetics of Tropical and Extra-Tropical Regions under Cold ENSO Compose Episodes. Open Access Library Journal, 4: e3566.

https://doi.org/10.4236/oalib.1103566

Received: March 27, 2017

Accepted: May 23, 2017

Published: May 26, 2017

Copyright $\odot 2017$ by author and Open Access Library Inc.

This work is licensed under the Creative Commons Attribution International License (CC BY 4.0). http://creativecommons.org/licenses/by/4.0/

\section{Open Access}

\begin{abstract}
The purpose of this study was to quantify and evaluate the effects of ENSO (El Niño Southern Oscillation) cold phases, throughout a composite of five intense La Niña episodes, on the atmospheric energetics of four distinct domains: $80^{\circ} \mathrm{S}-5^{\circ} \mathrm{N}$ (zone 1), $50^{\circ} \mathrm{S}-5^{\circ} \mathrm{N}$ (zone 2), $30^{\circ} \mathrm{S}-5^{\circ} \mathrm{N}$ (zone 3), and $30^{\circ} \mathrm{S}-$ $30^{\circ} \mathrm{N}$ (zone 4). Data from NCEP reanalysis-II were used in the reckoning of atmospheric energies in the mentioned areas. In the synthesis, in zones 2, 3 and 4, the results showed that production of zonal terms of potential energy and kinetic energy decreased, mainly due to decreases of the meridional temperature gradient. As a result the conversions between them and between zonal kinetic energy and eddy kinetic energy were also reduced. This behavior, however, has not led to a significant intensification of baroclinic branch, except for zone 4. Regarding zone 1, it was observed the most atypical set. That is, KZ was intensified even with the reduction of all the sources that contribute directly to its supply.
\end{abstract}

\section{Subject Areas}

Atmospheric Sciences

\section{Keywords}

Atmospheric Energetics, Lorenz Energy Cycle, ENSO, La Niña

\section{Introduction}

Studies related to atmospheric energetics involve knowledge of the energy transformations that occur in the planet's atmosphere. According to Lorenz [1], 
solar energy is converted into internal energy (related to temperature) plus potential energy (relative to geopotential height and mass), which can be considered as just one form of energy, named total potential energy. However, total potential energy, in turn, cannot be completely converted into kinetic energy as there is a limit on the occurrence of such transformation; that is, there is a portion of the energy that does not change. This portion is as the energy of the reference state, which is minimal and not available for conversion. The amount of energy available for conversion into another form of energy is the available potential energy. According to Lorenz's formulation, such energy and the kinetic energy can be further divided into a basic state and perturbations related to the basic state. The Energy terms represent the feature of atmospheric behavior (in terms of power generation and conversion), and hence its importance as the technique allows the possibility to calculate change related to intensity of atmospheric disturbances (in the synoptic scale, sub-synoptic and planetary scale) during a specific time interval. So, energetics is a powerful, versatile and robust technique that can be applied for purposes of studies involving the dynamics of the atmosphere, such as that associated with ENSO events, monsoons, greenhouse gases or aerosols, so that its application is quite wide.

For example, [2] analyzed the energy cycle in a region overlooked by the Walker Circulation and its relationship with strong episodes of ENSO. They concluded that for a composite of El Niño events the tropical atmosphere had an increase in zonal potential energy, a decrease of eddy potential energy, and a reduction in kinetic energy fields. For the composite of La Niña events, the tropical atmosphere displayed an increase the kinetic energy fields, contrasting to the opposite phase.

In 2010, [3] used in the study the dynamics of the atmospheric response relative to an increase in the $\mathrm{CO}_{2}$ concentration. They found a twofold role of the heating pattern characterized by a strong heating in the tropical upper troposphere and in the lower levels of high latitudes. They also concluded that this pattern causes an increase of the average potential energy in the upper troposphere and a decrease in the lower troposphere. In 2011 and 2012 [4] [5], they found that the weakening observed in the lower troposphere and the strengthening in the upper troposphere are associated with the conversion path $\mathrm{AZ} \rightarrow$ $\mathrm{AE} \rightarrow \mathrm{KE}$ (respectively, zonal available potential energy, eddy potential energy and eddy kinetic energy) and the dual-role heating is mainly due to the static stability parameter.

Another important work applying the Lorenz Energy Cycle (LEC) done by [6], analyzed the South American (SA) rainy season through the application of a multivariate Empirical Orthogonal Function (EOF) analysis to an SA gridded precipitation analysis and to the components of the LEC. The authors concluded that the predominance of the different LEC components at each phase of the South American Monsoon System (SAMS) are an indicator of the onset of the rainy season in terms of physical processes.

In a recent study, [7] verified the evolution of the Lorenz energy cycle in the Intertropical Convergence Zone (ITCZ) in the South American sector of the At- 
lantic. They found a strong annual cycle in all the energy components with high peaks in the austral summer. The zonal component of the kinetic energy (KZ) presented a decreasing trend between 1979 and 2007, while the other energy components did not present noticeable changes. A small increasing trend in the eddy energy components indicates strengthening of the eddies. They also found that the values of $\mathrm{KZ}$ and the values of the available potential eddy energy ( $\mathrm{AE}$ ) are significantly high during the period from 1982 to 1983 , indicating that the intense warm ENSO and/or the El Chichon eruption may have affected the circulation in the ITCZ region.

The aforementioned studies show the energetics applications, and in this context, the purpose of this paper is to compute the impact of La Niña events on Lorenz's Cycle for four different regions around the Earth. ENSO events are ocean-atmosphere interaction phenomena associated with changes in climatic patterns of the surface sea temperature, trade winds and emission of long wave radiation by the ocean in the Equatorial Pacific region. The physics of ENSO and its climatic consequences can be found in [8]-[15].

The main purpose of this work is to evaluate the effects of the strongest La Niña events on the energetics of specific Southern Hemisphere domains to quantify the horizontal impact extension related to this cold phases. Reference [2] shows that energetics effect of different ENSO phases is limited to the Walker circulation zone (a small piece of the tropical region). Differently from [2], who conducted the study for the tropical region that encompassed only the limits of the Walker circulation (latitude $5^{\circ} \mathrm{N}$ and $10^{\circ} \mathrm{S}$, longitude $120^{\circ} \mathrm{E}$ and $80^{\circ} \mathrm{W}$ ), in this paper, the study is conducted for regions located in tropical and extratropical regions. More, [2] focused their findings on the results obtained for two-dimensional analysis (pressure levels versus time), while this work investigated the temporal variation of integrated energy components in the atmospheric volume.

This paper is organized as follows: the next section introduces the data and methodology used for the study. Following, the results and discussion thereof are presented. Finally, we present the conclusions.

\section{Data and Methodology}

Data used in this study are from NCEP reanalysis-2/NCAR, as the Reanalysis data for the Southern Hemisphere is more reliable after 1979 [16] we limited our analysis to the period of 1979-2011 and refer to a period of 33 years taken from the NOAA-CIRES Climate Diagnostic Center, available at http://www.cpc.ncep.noaa.gov/. The data used here correspond to daily averages with $2.5^{\circ} \times 2.5^{\circ}$ horizontal resolution in latitude and longitude. The data span 12 levels of isobaric surfaces (1000, 925, 850, 700, 600, 500, 400, 300, 250, 200, 150, and $100 \mathrm{hPa}$ ) for geopotential height, temperature, zonal and meridional components of the velocity wind vector, and omega, the vertical component of this vector in pressure coordinates.

Based on the reanalysis data, calculations of the atmospheric calculations were performed for the whole zonal domain (0 to 360 degrees). It was used four different zones located at $80^{\circ} \mathrm{S}-5^{\circ} \mathrm{N}$ (region 1 ), $50^{\circ} \mathrm{S}-5^{\circ} \mathrm{N}$ (region 2 ), $30^{\circ} \mathrm{S}-5^{\circ} \mathrm{N}$ 
(region 3), and $30^{\circ} \mathrm{S}-30^{\circ} \mathrm{N}$ (region 4) in order to study the change of energy cycles during the occurrence of La Niña events. The main purpose of selecting different regions in the southern hemisphere is to evaluate the effects separately. For example, the horizontal extension of these particular cold ENSO events effects, since each domain must have a particular influence of the equatorial Pacific region, where the influence of ENSO is more direct. The selection of five La Niña events was based on the ONI (Oceanic Niño Index). This index classifies an event as a La Niña episode when the arithmetic average of SST anomalies of three consecutive months in the Niño 3.4 region is lower than $-0.5^{\circ} \mathrm{C}$ for five consecutive months. Based on the ONI index, the following events were selected: 1984-1985, 1988-1989, 1998-1999, 1999-2000, and 2010-2011. The composite in each domain was created based on the average of the atmospheric parameters of the five selected events. Then, energy was calculated for the composite as well as for the entire series of 33 years. The results for each area were obtained from a comparison between the composite of the energy cycle and its climatology. The comparison was done by percentage, which shall be calculated for the range from August (year 0) to April (the following year). Moreover, indicates how much each energy component increase or decrease (in La Niña events) in relation to climatology for the same period. The interval chosen for the study of the impact of La Niña events was the interval between August and April, because, our criterion was to select a period in which SST anomaly in the Niño 3.4 region remained below or equal to approximately $1^{\circ} \mathrm{C}$.

\section{Lorenz's Equations}

In the LEC, the four boxes correspond to each of the energy reservoirs and the arrows represent the conventional directions of generation, conversion, or energy dissipation (Figure 1).

GZ and GE are respectively the generation of zonal available potential energy and eddy available potential energy. $\mathrm{CZ}$ represents the conversion between zonal available potential energy and zonal kinetic energy through the upward movement of warm air and subsidence of cold air at different latitudes. This process indicates a negative correlation between zonal averages of $\omega$ and $\mathrm{T}$ and hence a

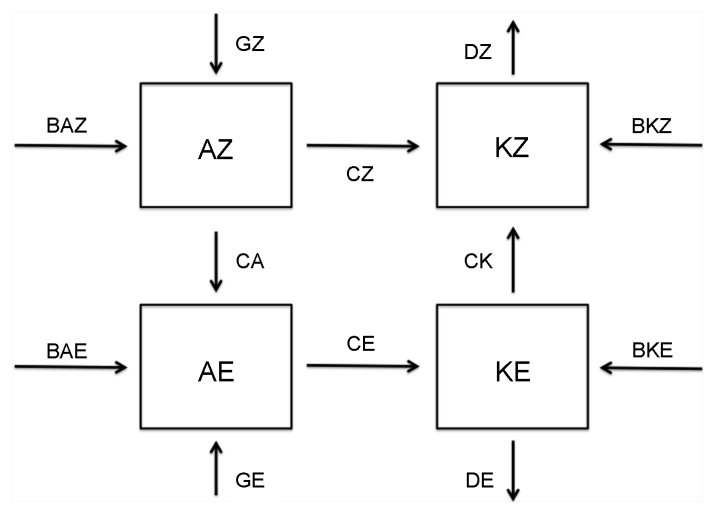

Figure 1. Lorenz energy diagram representative of a 4 boxes. 
positive CZ. That is, zonal available potential energy (AZ) is converted into zonal kinetic energy (KZ) in the thermally direct Hadley cell [4] [17]. CE (Equation (19)) already represents the upward movement of warm air and subsidence of cold air in the vertical plane in the same circle of latitude [18]. CA represents the transport of sensible heat, both meridionally and vertically, associated with meridional and vertical gradients of temperature [19]. From a physical standpoint, in the lower troposphere, zonal average temperature decreases toward the poles. The wavelike disturbances transport warmer air to cooler latitudes and colder air to warmer latitudes, reducing the meridional thermal gradients, and consequently reducing AZ. Because of this transport, along the same circle of latitude temperature, notable differences appear, thereby generating eddy available potential energy (AE) [20]. The term represents the terms of zonal momentum transport associated with perturbations along the meridional and vertical gradient of zonal wind and due to transports of momentum associated with perturbations along the meridional and vertical gradient of meridional wind [18]. The terms DZ and DE are the dissipation of the zonal kinetic energy and the kinetic energy of the disturbances, respectively. The equations below (Equations (2.1) to (2.4)), representing the conversion processes involved in the diagram, where terms on the left of the equality sign represent the rate of production or destruction of each energy reservoir.

$$
\begin{aligned}
& \frac{\partial \mathrm{AZ}}{\partial t}=-\mathrm{CA}-\mathrm{CZ}+\mathrm{BAZ}+\mathrm{GZ} \\
& \frac{\partial \mathrm{AE}}{\partial t}=\mathrm{CA}-\mathrm{CE}+\mathrm{BAE}+\mathrm{GE} \\
& \frac{\partial \mathrm{KZ}}{\partial t}=\mathrm{CK}+\mathrm{CZ}+\mathrm{BKZ}-\mathrm{DZ} \\
& \frac{\partial \mathrm{KE}}{\partial t}=\mathrm{CE}-\mathrm{CK}+\mathrm{BKE}-\mathrm{DE}
\end{aligned}
$$

The terms BAZ, BAE, BKZ and BKE are flows of energy across the boundary. $B A Z$ represents the flux through the boundary (B) of zonal available potential energy (AZ), BAE represents the flux through the boundary (B) of eddy available potential energy (AE), BKZ represents the flux through the boundary (B) of zonal kinetic energy (KZ) and BKE represents the flux through the boundary (B) of eddy kinetic energy (KE).

The above equations and those contained in the Appendix are part of the formalism developed by [21] for the equations of [1], and describe processes of transformation of potential and kinetic energies and their relationship with the terms of conversion, generation, and dissipation. The generation and dissipation terms were calculated as waste (Equations (2.5) and (2.6)) and the remaining terms will be integrated in 12 pressure levels, starting from the surface.

GZ and GE were calculated as in the equations below:

$$
\mathrm{GZ}=\mathrm{CZ}+\mathrm{CA}-\mathrm{BAZ}+\frac{\partial \mathrm{AZ}}{\partial t}
$$




$$
\begin{aligned}
& \mathrm{GE}=\mathrm{CE}-\mathrm{CA}-\mathrm{BAE}+\frac{\partial \mathrm{AE}}{\partial t} \\
& \mathrm{DZ}=-\frac{\partial \mathrm{KZ}}{\partial t}+\mathrm{CZ}+\mathrm{CK}+\mathrm{BKZ} \\
& \mathrm{DE}=-\frac{\partial \mathrm{KE}}{\partial t}-\mathrm{CK}+\mathrm{CE}+\mathrm{BKE}
\end{aligned}
$$

\section{Results and Discussion}

Figures 2-4 presents, respectively, a comparison between the temporal variations in terms of energy generation, energy reservoirs and energy conversions, with the composite of La Niñas for the regions 1, 2, 3, and 4, whose curves of variation are related to the left hand axis. On the right hand axis, the anomalies of energy production in each domain are shown. The sum of all energies produced between August and April and the sum of all the energies that crossed the boundary (only Figure 3 ) of the domain during this interval are displayed at the top of the graph. The graphs of the sums show only the total energy produced within the range, while the graphs of anomalies show, month by month, whether energy production was higher or lower compared to the climatology.

\subsection{Energy Generation Terms}

Figure 2(a) displays the temporal variation in zonal generation of available potential energy (GZ); it was observed reductions by approximately $1.50 \%$ in zone $1,1.59 \%$ in zone 3 and $8.90 \%$ in zone 4 . According to Winston and Krueger and

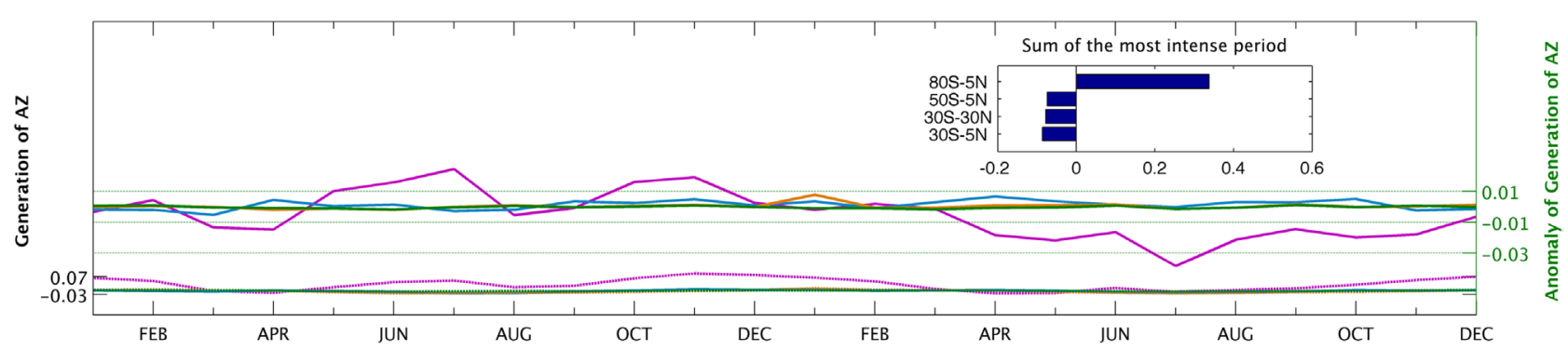

(a)

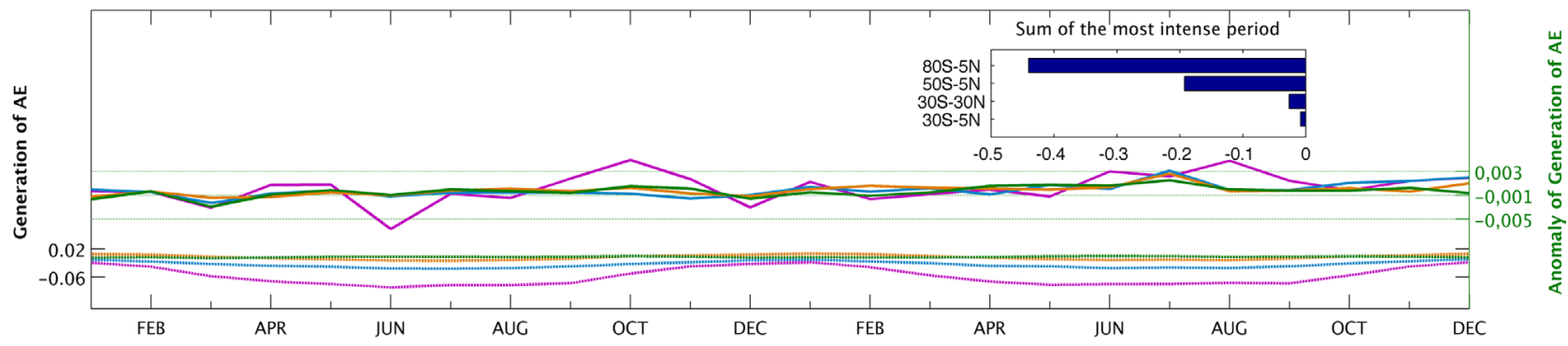

(b)

Figure 2. Temporal variation of anomalies of GZ (a) and GE (b) for composites of La Niña events for four different regions: Domain $80^{\circ} \mathrm{S}-5^{\circ} \mathrm{N}$ (pink line), domain $50^{\circ} \mathrm{S}-5^{\circ} \mathrm{N}$ (blue line), domain $30^{\circ} \mathrm{S}-5^{\circ} \mathrm{N}$ (orange line) and domain $30^{\circ} \mathrm{S}-30^{\circ} \mathrm{N}$ (green line). The bar graph in central shows the sum of all the energy produced between August and April for the term of generation (GE). At the bottom, dashed lines show the values of energy production for La Niña compounds in relation to each domain. Dashed lines of the domains are same colors of previous. Units are in $10^{5} \mathrm{~W} / \mathrm{m}^{2}$. 


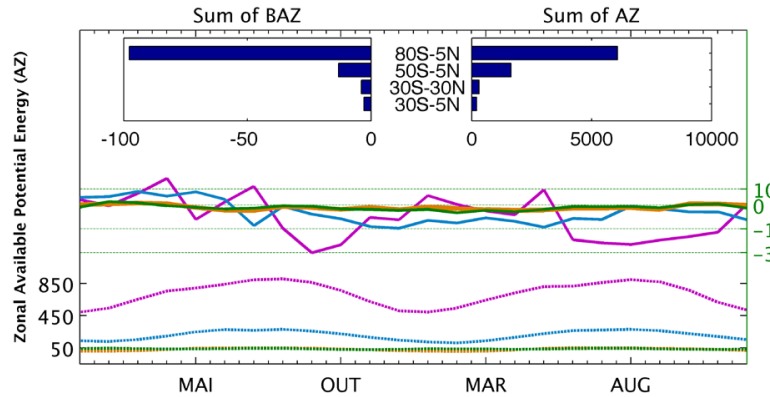

(a)

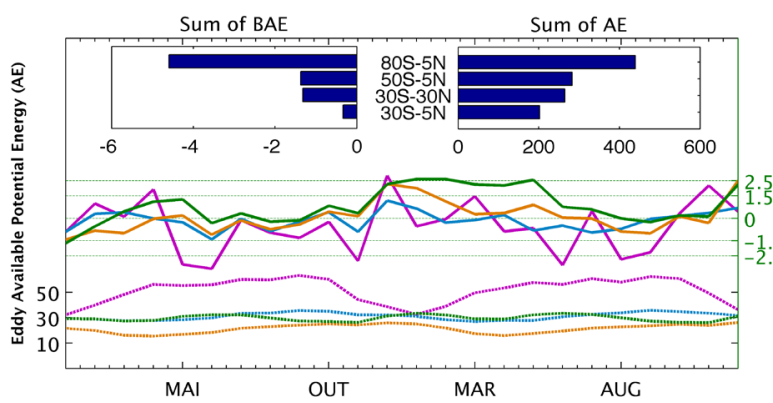

(c)

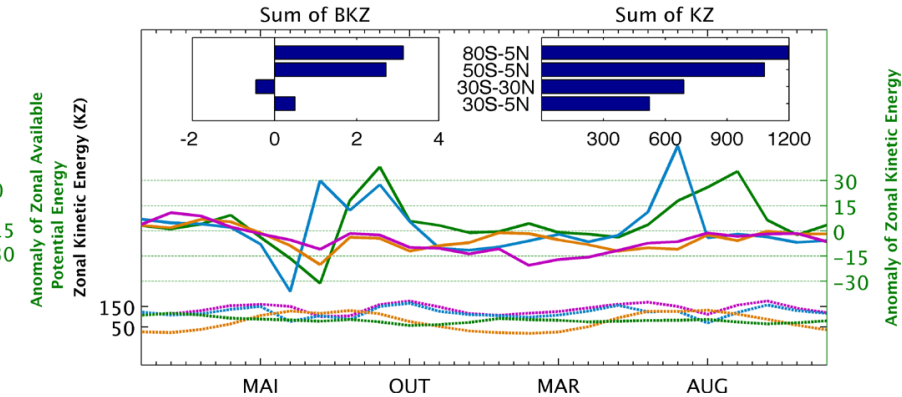

(b)

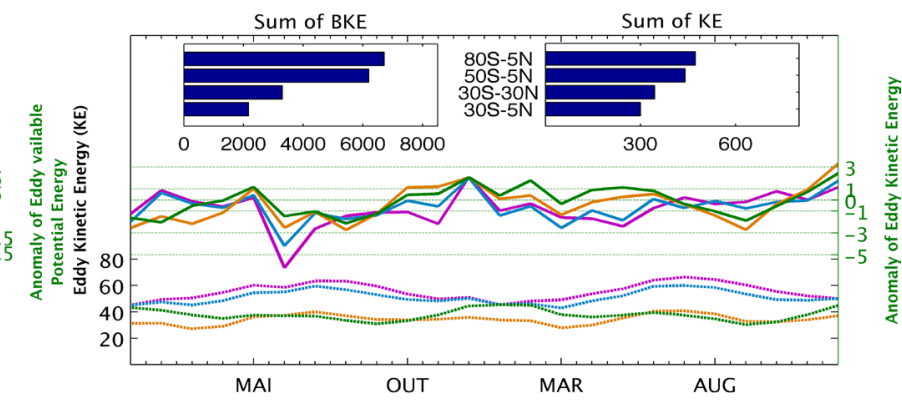

(d)

Figure 3. Temporal variation of anomalies of AZ (a), KZ (b), AE (c) and KE (d) for composites of La Niña events for four different regions: domain $80^{\circ} \mathrm{S}-5^{\circ} \mathrm{N}$ (pink line), domain $50^{\circ} \mathrm{S}-5^{\circ} \mathrm{N}$ (blue line), domain $30^{\circ} \mathrm{S}-5^{\circ} \mathrm{N}$ (orange line) and domain $30^{\circ} \mathrm{S}-$ $30^{\circ} \mathrm{N}$ (green line). The bar graphs in central and on the left corner show the sum of all the energy produced between August and April for the term of reservoir (KE) and boundary (BKE), respectively. At the bottom, dashed lines show the values of energy production for La Niña compounds in relation to each domain. Dashed lines of the domains are same colors of previous. Units are in $10^{5} \mathrm{~J} / \mathrm{m}^{2}$.

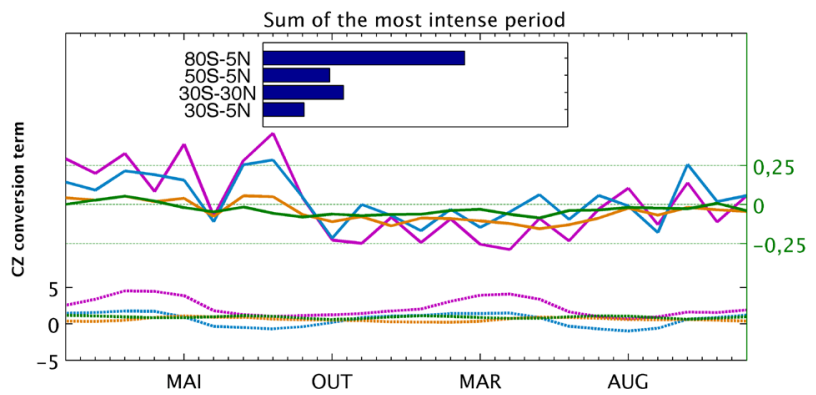

(a)

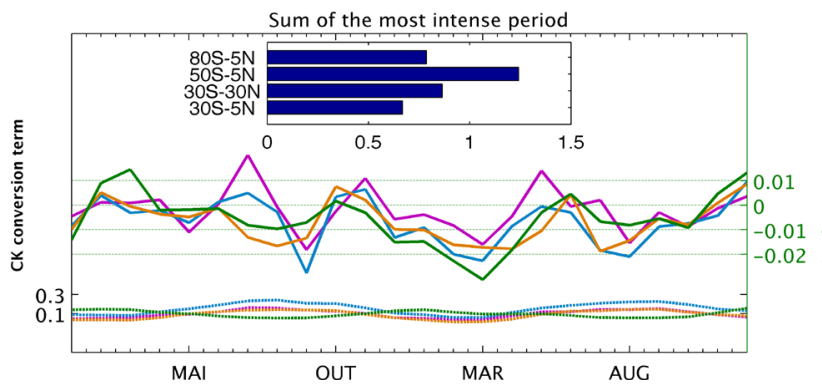

(c)

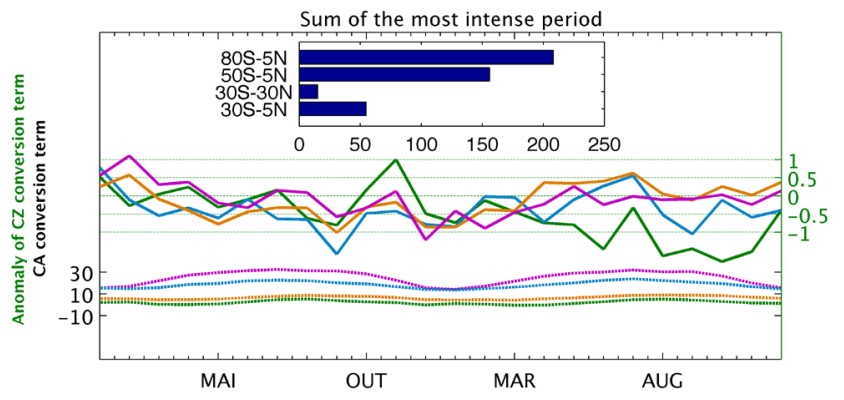

(b)

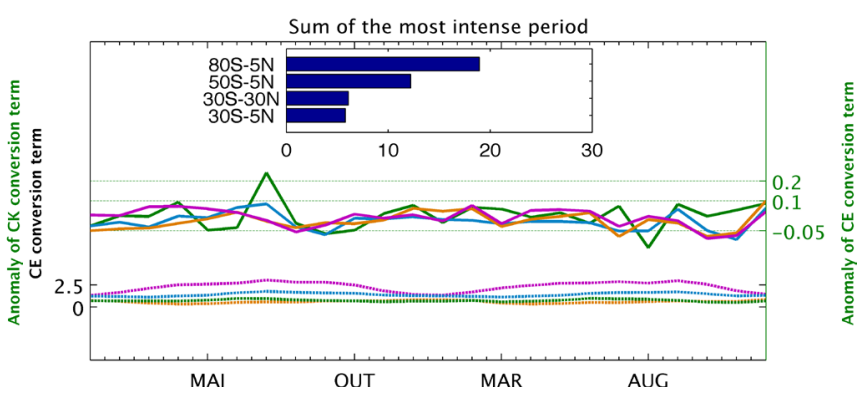

(d)

Figure 4. Temporal variation anomalies of CZ (a), CA (b), CK (c) and CE (d) for composite of La Niña events for four different regions: domain $80^{\circ} \mathrm{S}-5^{\circ} \mathrm{N}$ (pink line), domain $50^{\circ} \mathrm{S}-5^{\circ} \mathrm{N}$ (blue line), domain $30^{\circ} \mathrm{S}-5^{\circ} \mathrm{N}$ (orange line) and domain $30^{\circ} \mathrm{S}-30^{\circ} \mathrm{N}$ (green line). The bar graph in central shows the sum of all the energy produced between August and April for the term of conversion (CE). At the bottom, dashed lines show the values of energy production for La Niña compounds in relation to each domain. Dashed lines of the domains are same colors of previous. Units are in $\mathrm{W} / \mathrm{m}^{2}$. 
Brown [20] [22], differences in production of GZ are also due to differential heating of the atmosphere. In this case caused by an increase in latent heat flux in the tropical region, for the temporal evolution of GZ, was observed that between the months of August and December there was the largest increase in energy production when compared to the same climatological period, except for zone 1, which presented the highest reduction in energy production. The behavior of GE is observed in Figure 2(b). Zone 2 and zone 3 suffered a negligible increase. The greatest effects were in zones 1 and 4 showed weakening around $2.00 \%$ and $17.68 \%$, respectively. According to Brown [22], production of GE is due to the tendency of cold eddies be heated and warm eddies be cooled. The reduction indicates decrease in this trend. About zone 1, the highest energy production took place between September and November, that is, in the first phase of the studied interval. For zone 4 , the range of greater reduction was seen from December, returning to increase from April.

\subsection{Energy Reservoir Terms}

Figure 3(a) shows the production of zonal available potential energy (AZ), which showed weakness by about $1.47 \%$ (zone 1), $4.85 \%$ (zone 2), $8.67 \%$ (zone 3 ) and $7.81 \%$ (zone 4). Except for domain 1, the predominance of negative anomalies was seen in the second half of the range (between December and April). This allows us to suggest that tropical zones were more affected than the others did. Our results suggest that La Niña episodes may be able to show a decrease in the display of $\mathrm{AZ}$, which in turn is associated with a weakening in meridional temperature gradient. Also based on these results, the weakness of AZ energy observed in the tropical atmosphere is in agreement with the results found by [2]. For all areas, there was strong reduction in AZ's production for the whole period of La Niña, but for the zones 2, 3 and 4 the major reduction was observed from December. For zone 1, the largest reduction was checked between August and December.

Figure 3(b) shows the production of zonal kinetic energy (KZ), which was reduced by about $9.11 \%$ (zone 3), and $12.90 \%$ (zone 4 ) and intensified by about $5.80 \%$ (zone 1), for zone 2, it was observed a tiny reduction. Except for domain 1 , it was observed predominance of negative anomalies. In zones 2 and 4 , those anomalies were more intense in the second half of the range (between December and April), and in zone 3 the most intense anomalies were observed in the first half of the interval. Regarding to the temporal evolution of $\mathrm{KZ}$ production, it can be said that: the four areas showed different behavior. In zone 1, the range of greater energy production was concentrated between August and November, after that energy production levels are very close to the climatological values and only at the end of the event presented another significant increase in the production of KZ. For zones 3 and 4, the reduction in KZ dominated the entire La Niña event; however, the larger reduction in zone 3 was seen between August and December, whereas for zone 4, the major reduction was observed starting from December. According to Kim and Kim [23], KZ production is related to the jet 
streams in the troposphere and the stratosphere, where there is a maximum production located in the tropics, which corroborates the more significant results in zones 3 e 4 .

In Figure 3(c), the greatest effect of the composite of La Niña occurred in zones 3 and 4, which showed weakening by about $2.77 \%$ and 5.05\%, respectively. In these zones, at the first months of the range AE's production decreased, and only from December it increases, persisting up to half of the year $0+1$. In other zones ( 1 and 2 ), the effect of La Niña was not even $1 \%$. In general there is a predominance of positive anomalies and these become more intense over the range, that is, between December and April of year $0+1$ (the second half of the interval) and coincides with the period of lower production of AZ, except for zone 4 . The strengthening of $\mathrm{AE}$ in zones 3 and 4 is consistent with the results of [2], which found that $\mathrm{AE}$ production in the tropical atmosphere increases the occurrence of La Niña. Furthermore, [17] suggested that the pattern of AE production is related to the continent-ocean thermal contrast. According to our results, it can be said that in the occurrence of events like La Niña, the thermal contrast is affected mostly in the region of tropical latitudes (zones 3 and 4) rather than in regions including middle and high latitudes (zones 1 and 2).

The production of eddy kinetic energy (KE) can be seen in Figure 3(d). KE decreased in zones 1 , and 2 (1.74\% and 1.63\%, respectively), in zone 3 and 4; it wasn't observed increase or decrease considerable. Zones 1 and 2 were marked by a reduction in the entire La Niña composite event. This behavior was not different within the study period (August to April), where there was only one occurrence of intensification, concentrated in December. The weakening must be related to the slowdown of tropospheric and stratospheric jet streams during La Niña years [24], generating a decrease in KE at mid-latitudes in the Southern Hemisphere.

\subsection{Energy Conversion Terms}

Figure 4(a) shows the behavior of conversion between the zonal energy forms $\mathrm{AZ}$ and $\mathrm{KZ}(\mathrm{CZ})$. CZ was reduced in all areas: by about $4.51 \%$ (zone 1), 5.00\% (zone 2), $15.48 \%$ (zone 3 ), and $6.22 \%$ (zone 4 ). This weakening is probably associated with a slowdown of the sensible heat transport due to decreased vertical and meridional gradients of temperature and was higher in domain 3 due to the weakening of the Hadley cell of Southern hemisphere located at $30^{\circ} \mathrm{S}$. In domain 4 , the weakening effects of the Hadley circulation of each hemisphere cancel each other out and $\mathrm{CZ}$ weakening is primarily driven by the decrease in the meridional temperature gradient, justifying the proximity in the percentages of weakening in domains 1,2 and 4 . This condition should lead to a gain of KE through the $\mathrm{CE}$ conversion, because more zonal available potential energy would be used to produce eddy available potential energy instead of zonal kinetic energy, but only in zone 4 this intensification is observed. In zones 1, 2 and 3, KE was weakened. This result is due to the high value of boundary flux of KE (BKE), which made the eddy kinetic energy values negative within these areas of study. 
In relation to the values of CZ's we can observe that there is a certain level of similarity among the four regions. The La Niña composite event begins with high production of CZ, which lasts until the middle of the event. In September, the production begins to decrease and persists until the end of La Niña.

In Figure 4(b), it can be seen that there is a conversion between the forms of the available potential energy (CA). The largest effect of the composite for the La Niña occurred in zones 1 and 4, which showed weakening by about $1.56 \%$, $10.53 \%$, respectively. In other areas, the effect of La Niña was not even $1 \%$. In these areas, the temporal variation of CA was marked by variation between increase and decrease of CA. The initial phase marked by a large reduction in CA production, which remains until November of the year 0 . The decrease in CA output is related to the reduction of the horizontal and vertical transport of heat through eddies.

According to Figure 4(c) it can be observed that CK was weakened in all areas: by about $5.88 \%$ (zone 1), $7.04 \%$ (zone 2), $12.05 \%$ (zone 3), and $12.11 \%$ (zone 4), suggesting a reduction equatorward of the positive contributions of tropospheric jets and stratospheric polar-night jets, as was suggested by [25]. Moreover, a weakening of zonal motion because of the poleward transport of momentum by the motion of eddies, as suggested by [23]. It was observed a strong reduction in the temporal variation of $\mathrm{CK}$, where the most intense variations occurred in the second half of the event.

The conversion between eddy modes (CE) for the studied domains is presented in Figure 4(d). It can be observed that the values of CE strengthened by about, $1.63 \%$ (zone 3 ) and 1.85\% (zone 4). For zones 1 and 2, it wasn't observed considerable increase or decrease. In zone 3 , there is great variation in the production of energy for the whole duration of La Niña event, with little reduction in the production of CE. Between August and April, it could be see that the first interval phase is marked by a decrease of CE in the first three months, followed by an increase in energy production that prevails until the end of La Niña. And in zone 4, the major fluctuations in energy production occur between July and January of initial phase, and this behavior tends to repeat itself in the mature stage of the event. The increase in CE production indicates that more energy is being converted into eddy kinetic energy during the occurrence of La Niña. This intensification is probably associated with the large differences of temperature at the same latitude, because $\mathrm{CE}$ is the result of warm air rising and cold air sinking, at the same circle of latitude, in the vertical plane.

\subsection{Volume Integrated Energy Cycle}

The Lorenz energy cycle for the climatology and La Niña years, for the interval between August and April, is shown in Figure 5. The convention of the conversion cycle is given by the direction of the arrows as in Figure 1. As can be seen from the diagram, it was noted that the energy cycle as a whole was weakened during La Niña years. Furthermore, the energy diagram reveals that the weaker Lorenz energy cycle results from a decrease in the most conversion terms during 


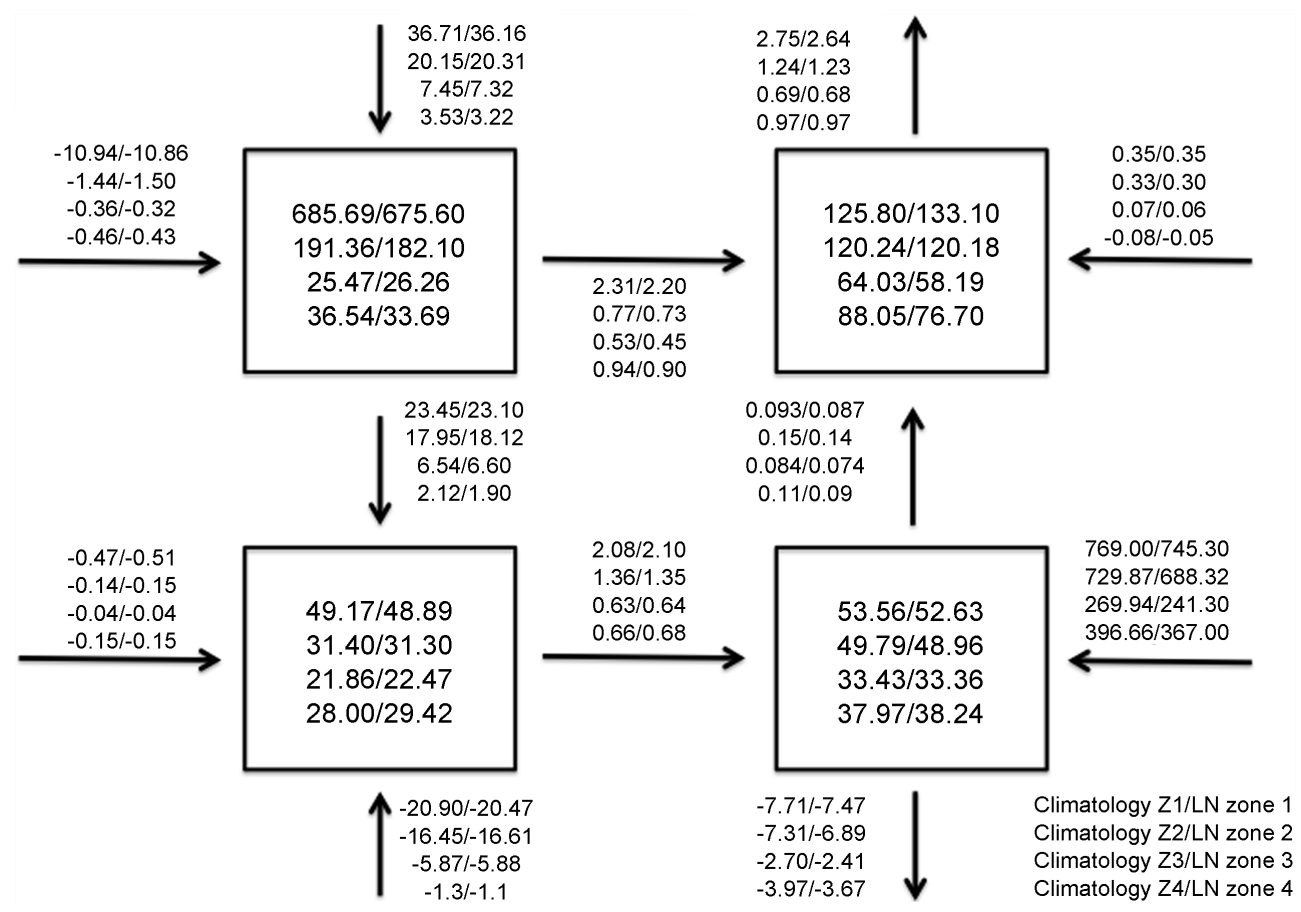

Figure 5. Lorenz energy cycle for the climatology and La Niña composite. All values are representative of the interval between August and April. Units are $10^{5} \mathrm{~J} / \mathrm{W}^{2}$ for energy terms and $\mathrm{W} / \mathrm{m}^{2}$ for conversion and flux terms. All conventions follow the standard diagram outlined in Figure 1.

La Niña events.

The boundary flux of $\mathrm{AZ}(\mathrm{BAZ})$ and $\mathrm{AE}(\mathrm{BAE})$ are negatives in all zones, working as a sink of zonal and eddy available energy. Both terms undergo import changes for the La Niña composite. However, due to their low magnitudes relative to the other terms (mainly, zone 2, 3 and 4) in the energy balance, their contributions to the energy reservoirs are less expressive. Climatologically, BKZ acts as a sink of KZ. As can be seen, BKZ keeps this feature during La Niña years. The boundary flux of KE (BKE) is positive, showing that this term contributes to the rising of KE fin all zones. Its contribution is reduced for La Niña years.

\section{Conclusions}

This is the first time that Lorenz Energy Cycle is used to evaluate and compare four different zones around the Earth located in the tropical and extratropical regions. We have computed the impact of the cold phase of ENSO on the atmospheric energetics of four domains around the world, commonly affected by La Niña episodes.

It was observed that generation of zonal available potential energy (GZ) was reduced (zones 3 and 4), most likely associated with an increase in the latent heat flux in tropical regions. And generation of eddy available potential energy decreased in zones 1 and 2, probably due to weakening of tendency of cold eddies to be warmed and warm eddies to be cooled, and this effect is more intense in zone 4 which surrounding the Hadley Cells of the two hemispheres. 
$\mathrm{AZ}$ decreased in all zones, and the tropical region domains (3 and 4) were the most affected. The most interesting results for AE were intensification of zones 3 and 4, reaffirming that events like La Niña affect more the thermal contrast in the tropics, and the $\mathrm{CE}$ results also confirm that, with the increase in zones 3 and 4. As for other conversion terms, $\mathrm{CK}$ and $\mathrm{CZ}$ weakening in all zones, and $\mathrm{CA}$ weakened in zones 1 and 4 , while for the other zones it was observed values very close to the climatology.

About the zonal kinetic energy, in zone 1 there was an intensification of $\mathrm{KZ}$, despite $\mathrm{CZ}$ and $\mathrm{CK}$ have been reduced. However, the zonal kinetic energy dissipation (DZ) decreased within the range. Therefore, less zonal kinetic energy was dissipated in La Niña composite, which justifies the fact that in these events the amount of KZ energy is larger than in climatology. For others zones, DZ did not affect enough the amount of $\mathrm{KZ}$ energy into the reservoir. $\mathrm{KE}$ decreased in zones 1 and 2 mainly due reductions in source term, BKE. Since it was observed reduction in the sink terms, DE and CK (CE wasn't increased or decreased considerably for zones 1 and 2). The weakening must be related to the slowdown of tropospheric and stratospheric jet streams during La Niña years.

Overall, zones including tropical regions proved to be the most affected by the occurrence of La Niña events than zones, which include middle and high latitudes.

Making some comparisons between this work and that done by [2] it is observed that they computed the energetics for the Pacific Walker Circulation to an area limited by the latitudes of $10^{\circ} \mathrm{S}$ and $5^{\circ} \mathrm{N}$, and longitudes $120^{\circ} \mathrm{E}$ and $80^{\circ} \mathrm{W}$. While we made the study for four different zones located in tropical and extratropical regions $\left(\left(80^{\circ} \mathrm{S}-5^{\circ} \mathrm{N}\right.\right.$ (region 1$), 50^{\circ} \mathrm{S}-5^{\circ} \mathrm{N}$ (region 2$), 30^{\circ} \mathrm{S}-5^{\circ} \mathrm{N}$ (region 3), and $30^{\circ} \mathrm{S}-30^{\circ} \mathrm{N}$ (region 4)). In general, Veiga et al. 2013 found intensification of the energy cycle (considering volume integrated Energy Cycle for December, January and February), while we observed, in general, a weakening of the energy cycle due to the occurrence of La Niña. Zones 1 and 2 showed the largest differences, almost all components of energy decreased for La Niña events. Furthermore, zones 3 and 4, located in the tropical region, showed similarities to $\mathrm{AE}, \mathrm{CE}$ and $\mathrm{CK}$. In zone 4 the difference between our results and those presented by [2] is only the weakening on branch $\mathrm{AZ} \rightarrow \mathrm{CZ} \rightarrow \mathrm{KZ}$. Moreover, the weakening of this branch was observed in all zones except 1 . These results show that the occurrence of La Niña 1) weakens the south temperature gradient, which generates a decrease in the production of available potential energy in the basic state, consequently weakened barotropic branch $\mathrm{AZ} \rightarrow \mathrm{KZ}$, and 2) as the climatological $\mathrm{KZ}$ production is related to the jet streams in the troposphere and the stratosphere, where there is a maximum production starting at $30^{\circ} \mathrm{N}$ which can reach $30^{\circ} \mathrm{S}$. This suggests that the occurrence of La Niña weakens the tropospheric and stratospheric jets, leading to a further weakening of the KZ production in the regions located in tropical latitudes.

These results add knowledge both for the studies focused on the effects of ENSO events on the atmospheric circulation dynamics, and for studies interest- 
ed in changes in Lorenz cycle due to an atmospheric disturbance. Further studies may consider different scenarios of global warming plus the occurrence of ENSO events in order to verify the impacts on global energy and its consequences on the atmosphere.

\section{Acknowledgements}

The first author of this paper thanks CAPES for its financial support. The authors thank the two anonymous reviewers who have enriched the paper quality from their relevant questions and suggestions of improvements.

\section{Internet Resources}

SST's Data source,

http://www.cpc.ncep.noaa.gov/products/analysis_monitoring/ensostuff/ensoyea rs.shtml.

\section{References}

[1] Lorenz, E.N. (1955) Available Potential Energy and the Maintenance of the General Circulation. Tellus, 7, 157-167.

[2] Veiga, J.A.P., Pezza, A.B., Ambrizzi, T., Rao, V.B., Franchito, S.H. and Yoshida, M.C. (2013) The Energy Associated to the Pacific Walker Circulation and Its Relationship to ENSO. Atmospheric and Climate Sciences, 3, 627-642.

[3] Deckers, D.H. and von Storch, J.C. (2010) Energetics Response to Increases in Greenhouse Gas Concentration. Journal of Climate, 23, 3840-3887.

[4] Deckers, D.H. and von Storch, J.C. (2011) The Energetics Response to a Warmer Climate: Relative Contributions from the Transient and Stationary Eddies. Earth System Dynamics, 2, 105-120. https://doi.org/10.5194/esd-2-105-2011

[5] Deckers, D.H. and von Storch, J.C. (2012) Impact of Warming Pattern on Global Energetics. Journal of Climate, 33, 5223-5240. https://doi.org/10.1175/JCLI-D-11-00468.1

[6] Gutierrez, E.R., Dias, P.L.S., Veiga, J.A., Camayo, R. and dos Santos, A. (2009) Multivariate Analysis of the Energy Cycle of the South American Rainy Season. International Journal of Climatology, 29, 2256-2269.

[7] Da Silva, L.A. and Satyamurty, P. (2013) Evolution of the Lorenz Energy Cycle in the Intertropical Convergence Zone in the South American Sector of the Atlantic Ocean. Journal of Climate, 26, 3466-3481. https://doi.org/10.1175/JCLI-D-11-00426.1

[8] Horel, J.D. and Wallace, J.M. (1981) Planetary Scale Atmospheric Phenomena Associated with the Southern Oscillation. Monthly Weather Review, 109, 813-829. https://doi.org/10.1175/1520-0493(1981)109<0813:PSAPAW>2.0.CO;2

[9] van Loon, H. and Madden, R.A. (1981) The Southern Oscillation. Part I: Global Associations with Pressure and Temperature in Northern Winter. Monthly Weather Review, 109, 1150-1162. https://doi.org/10.1175/1520-0493(1981)109<1150:TSOPIG>2.0.CO;2

[10] Rasmusson, E.M. and Carpenter, T.H. (1982) Variations in Tropical See Surface Temperature and Surface Wind Fields Associated with the Southern Oscillation/El Niño. Monthly Weather Review, 110, 354-384. https://doi.org/10.1175/1520-0493(1982)110<0354:VITSST>2.0.CO;2 
[11] Kousky, V.E., Kagano, M.T. and Cavalcanti, I.F.A. (1984) A Review of the Southern Oscillation: Oceanic-Atmospheric Circulation Changes and Related Rainfall Anomalies. Tellus A: Dynamic Meteorology and Oceanography, 36, 490-504. https://doi.org/10.3402/tellusa.v36i5.11649

[12] Ropelewski, C.F. and Halpert, M.S. (1987) Global and Regional Scale Precipitation Patterns Associated with the El Niño/Southern Oscillation. Monthly Weather Review, 115, 1606-1626. https://doi.org/10.1175/1520-0493(1987)115<1606:GARSPP>2.0.CO;2

[13] Kane, R.P. (2008) Spatial and Temporal Characteristics of Outgoing Longwave Radiation (OLR): An Update. Brazilian Magazine of Geophysics, 26, 227-236.

[14] Grimm, A.M. and Tedeschi, R.G. (2009) ENSO and Extreme Rainfall Events in South America. Journal of Climates, 22, 1589-1609. https://doi.org/10.1175/2008jcli2429.1

[15] Yeh, S.W., Kug, J.S., Dewitte, B., Kwon, M.H., Kirtman, B.P. and Jin, F.F. (2009) El Niño in a Changing Climate. Nature, 461, 511-514. https://doi.org/10.1038/nature08316

[16] Kistler, R., Kalnay, E., Collins, W., Saha, S., White, G., Woollen, J., Chelliah, M., Ebisuzaki, W., Kanamitsu, M., Kousky, V., Dool, H.V., Jenne, R. and Fiorino, M. (2001) The CEP-NCAR 50-Year Reanalysis: Monthly Means CD-ROM and Documentation. Bulletin of the American Meteorological Society, 82, 247-267. https://doi.org/10.1175/1520-0477(2001)082<0247:TNNYRM>2.3.CO;2

[17] Li, L., Ingersoll, A.P., Jiang, X., Feldman, D. and Yung, Y.L. (2007) Lorenz Energy Cycle of the Global Atmosphere Based on Reanalysis Datasets. Geophysical Research Letters, 34, L16813. https://doi.org/10.1029/2007gl029985

[18] Marques, C.A.F., Rocha, A. and Corte-Real, J. (2011) Global Diagnostic of Five State-of-the-Art Climate Models. Climate Dynamics, 36, 1767-1794. https://doi.org/10.1007/s00382-010-0828-9

[19] Wiin-Nielsen, A., Brown, J.A., Drake, M. (1963) On Atmospheric Energy Conversions between the Zonal Flow and the Eddies. Tellus, 15, 261-279. https://doi.org/10.3402/tellusa.v15i3.8845

[20] Winston, J.S. and Krueger, A.F. (1961) Some Aspects of a Cycle of Available Potential Energy. Monthly Weather Review, 89, 307-318. https://doi.org/10.1175/1520-0493-89.9.307

[21] Krishnamurti, T.N. and Bounoua, L. (1996) An Introduction to Numerical Predictions Techniques. CRC Press, Boca Raton.

[22] Brown, J.A. (1964) A Diagnostic of Tropospheric Diabatic Heating and the Generation of Available Potential Energy. Tellus A: Dynamic Meteorology and Oceanography, 16, 371-388. https://doi.org/10.1111/j.2153-3490.1964.tb00174.x

[23] Kim, Y.H. and Kim, M.K. (2013) Examination of the Global Lorenz Energy Cycle Using MERRA and NCEP-Reanalysis 2. Climate Dynamics, 40, 1499-1513. https://doi.org/10.1007/s00382-012-1358-4

[24] Fedorova, N. and Carvalho, M.H. (2000) Synoptic Processes in La Niña and El Niño Years. Part II: Frontal Zones. Brazilian Magazine of Meteorology, 15, 57-72.

[25] Marques, C.A.F., Rocha, A. and Corte-Real, J. (2010) Comparative Energetics of ERA-40, JRA-25 and NCEP-R2 Reanalysis, in the Wave Number Domain. Dynamics of Atmospheres and Oceans, 50, 375-399. 


\section{Appendix}

Zonal mean of variable $X$ between longitudes $\lambda_{1}$ and $\lambda_{2}$ is given by:

$$
[X]_{\lambda}=\frac{1}{\lambda_{2}-\lambda_{1}} \int_{p_{1}}^{p_{2}} X \mathrm{~d} \lambda
$$

The zonal deviation field is given by:

$$
(X)_{\lambda}=X-[X]_{\lambda}
$$

Mean of $X$ in an area surrounded by longitudes $\lambda_{1}$ and $\lambda_{2}$ and latitudes $\phi_{1}$ e $\phi_{2}$ is given by:

$$
[X]_{\lambda \phi}=\frac{1}{\lambda_{2}-\lambda_{1}} \frac{1}{\sin \phi_{2}-\sin \phi_{1}} \int_{\phi_{1}}^{\phi_{2}} \int_{p_{1}}^{p_{2}} X \cos \phi \mathrm{d} \lambda \mathrm{d} \phi
$$

The deviation from the average in the area is given by:

$$
\left([X]_{\lambda}\right)_{\phi}=[X]_{\lambda}-[X]_{\lambda \phi}
$$

The four terms of energy reservoirs are given by:

$$
\begin{gathered}
\mathrm{AZ}=\int_{p_{1}}^{p_{2}} \frac{\left[\left([T]_{\lambda}\right)_{\phi}^{2}\right]_{\lambda \phi}}{2[\sigma]_{\lambda \phi}} \mathrm{d} p \\
\mathrm{AE}=\int_{p_{1}}^{p_{2}} \frac{\left[(T)_{\lambda}^{2}\right]_{\lambda \phi}}{2[\sigma]_{\lambda \phi}} \mathrm{d} p \\
\mathrm{KZ}=\int_{p_{1}}^{p_{2}} \frac{\left[[u]_{\lambda}^{2}+[v]_{\lambda}^{2}\right]_{\lambda \phi}}{2 g} \mathrm{~d} p \\
\mathrm{KE}=\int_{p_{1}}^{p_{2}} \frac{\left[(u)_{\lambda}^{2}+(v)_{\lambda}^{2}\right]_{\lambda \phi}}{2 g} \mathrm{~d} p
\end{gathered}
$$

The four conversion terms are given by:

$$
\begin{gathered}
\mathrm{CZ}=\int_{p_{1}}^{p_{2}}-\left[\left([\omega]_{\lambda}\right)_{\phi}\left([T]_{\lambda}\right)_{\phi}\right]_{\lambda \phi} \frac{R}{g p} \mathrm{~d} p \\
\mathrm{CA}=\int_{p 1}^{p_{2}}\left[\frac{(v)_{\lambda}(T)_{\lambda}}{2[\sigma]_{\lambda \phi} r} \frac{\partial\left([T]_{\lambda}\right)}{\partial \phi}\right]_{\lambda \phi} \mathrm{d} p+\left[\frac{(\omega)_{\lambda}(T)_{\lambda}}{p^{R / c_{p}}} \frac{\partial\left([T]_{\lambda}\right)_{\phi} p^{R / c_{p}}}{\partial p[\sigma]_{\lambda \phi}}\right]_{\lambda \phi} \mathrm{d} p \\
\mathrm{CE}=\int_{p 1}^{p_{2}}-\left[(\omega)_{\lambda}(T)_{\lambda}\right]_{\lambda \phi} \frac{R}{g p} \mathrm{~d} p \\
\mathrm{CK}=\int_{p_{1}}^{p_{2}} \frac{1}{g}\left[(v)_{\lambda}(u)_{\lambda} \frac{\cos \phi}{r} \frac{\partial[u]_{\lambda}}{\partial \phi \cos \phi}\right]_{\lambda \phi} \mathrm{d} p \\
+\int_{p_{1}}^{p_{2}} \frac{1}{g}\left[\frac{(v)_{\lambda}^{2}}{r} \frac{\partial[v]_{\lambda}}{\partial \phi}\right]_{\lambda \phi} \mathrm{d} p+\int_{p_{1}}^{p_{2}} \frac{1}{g}\left[[v]_{\lambda}(u)_{\lambda}^{2} \frac{\tan \phi}{r}\right]_{\lambda \phi} \mathrm{d} p \\
+\int_{p_{1}}^{p_{2}} \frac{1}{g}\left[(\omega)_{\lambda}(u)_{\lambda} \frac{\partial[u]_{\lambda}}{\partial p}\right]_{\lambda \phi} \mathrm{d} p+\int_{p_{1}}^{p_{2}} \frac{1}{g}\left[(\omega)_{\lambda}(v)_{\lambda} \frac{\partial[v]_{\lambda}}{\partial p}\right]_{\lambda \phi} \mathrm{d} p
\end{gathered}
$$


The energy transport integrals are:

$$
\begin{aligned}
& \mathrm{BAZ}=c_{1} \int_{p_{1}}^{p_{2}} \int_{\lambda_{1}}^{\lambda_{2}} \frac{1}{2[\sigma]_{\lambda \phi}}\left(2\left([T]_{\lambda}\right)_{\phi}(T)_{\lambda} u+\left([T]_{\lambda}\right)_{\phi}^{2} u\right) \mathrm{d} \phi \mathrm{d} p \\
& +c_{2} \int_{p_{1}}^{p_{2}} \frac{1}{2[\sigma]_{\lambda \phi}}\left(2\left[(v)_{\lambda}(T)_{\lambda}\right]_{\lambda}\left([T]_{\lambda}\right)_{\phi} \cos \phi+\left([T]_{\lambda}\right)_{\phi}^{2}[v]_{\lambda} \cos \phi\right) \mathrm{d} p \\
& -\frac{1}{2[\sigma]_{\lambda \phi}}\left(\left[2(\omega)_{\lambda}(T)_{\lambda}\right]_{\lambda}\left([T]_{\lambda}\right)_{\phi}+\left[[\omega]_{\lambda}\left([T]_{\lambda}\right)_{\phi}^{2}\right]_{\lambda \phi}\right) \\
& \mathrm{BAE}=c_{1} \int_{p_{1}}^{p_{2}} \int_{\phi_{1}}^{\phi_{2}} \frac{1}{2[\sigma]_{\lambda \phi}}\left[u(T)_{\lambda}^{2}\right] \mathrm{d} \phi \mathrm{d} p \\
& +c_{2} \int_{p_{1}}^{p_{2}} \frac{1}{2[\sigma]_{\lambda \phi}}\left(\left[(T)_{\lambda}^{2}\right]_{\lambda} \cos \phi\right) \mathrm{d} p-\left(\frac{\left[\omega(T)_{\lambda}^{2}\right]_{\lambda \phi}}{2[\sigma]_{\lambda \sigma}}\right) \\
& \mathrm{BKZ}=c_{1} \int_{p_{1}}^{p_{2}} \int_{\phi_{1}}^{\phi_{2}} \frac{1}{2 g}\left(u\left[u^{2}+v^{2}-(u)_{\lambda}^{2}-(v)_{\lambda}^{2}\right]\right) \mathrm{d} \phi \mathrm{d} p \\
& +c_{2} \int_{p_{1}}^{p_{2}} \frac{1}{2 g}\left(\left[v \cos \phi\left[u^{2}+v^{2}-(u)_{\lambda}^{2}\right]\right]_{\lambda}\right) \mathrm{d} p \\
& -\left(\frac{1}{2 g}\left[\omega\left[u^{2}+v^{2}-(u)_{\lambda}^{2}-(v)_{\lambda}^{2}\right]\right]_{\lambda \phi}\right) \\
& \mathrm{BKE}=c_{1} \int_{p_{1}}^{p_{2}} \int_{\phi_{1}}^{\phi_{2}} \frac{1}{2 g}\left(u\left[(u)_{\lambda}^{2}+(v)_{\lambda}^{2}\right]\right) \mathrm{d} \phi \mathrm{d} p \\
& +c_{2} \int_{p_{1}}^{p_{2}} \frac{1}{2 g}\left(\left[v \cos \phi\left[(u)_{\lambda}^{2}+\left((v)_{\lambda}^{2}\right)\right]\right]_{\lambda}\right) \mathrm{d} p \\
& -\left(\frac{1}{2 g}\left[\omega\left[(u)_{\lambda}^{2}+(v)_{\lambda}^{2}\right]\right]_{\lambda \phi}\right)
\end{aligned}
$$

where

$$
\begin{gathered}
C_{1}=-\left[r\left(\lambda_{2}-\lambda_{1}\right)\left(\sin \varphi_{2}-\sin \varphi_{1}\right)\right]^{-1} \\
C_{2}=-\left[r \times\left(\sin \varphi_{2}-\sin \varphi_{1}\right)\right]^{-1}
\end{gathered}
$$

where $p_{1}$ and $p_{2}$ are, respectively, the maximum and minimum pressure, $T$ is temperature, $g$ is the magnitude of gravity's acceleration, $r$ is the average radius of Earth, $u$ and $v$ are the zonal and meridional components of wind vector, respectively and $\sigma$ is the static stability parameter given by:

$$
[\sigma]_{\lambda \phi}=\left[\frac{g T}{c_{p}}-\frac{g p}{R} \frac{\partial T}{\partial p}\right]_{\lambda \phi}
$$


Submit or recommend next manuscript to OALib Journal and we will provide best service for you:

- Publication frequency: Monthly

- 9 subject areas of science, technology and medicine

- Fair and rigorous peer-review system

- Fast publication process

- Article promotion in various social networking sites (LinkedIn, Facebook, Twitter, etc.)

- Maximum dissemination of your research work

Submit Your Paper Online: Click Here to Submit

Or Contact service@oalib.com 